\title{
Land Treatment Exploration Tool
}

\section{Learning from the past to improve future restoration and rehabilitation actions}

\section{An adaptive management and decision support tool for land treatment planning.} The tool is available at https://www.usgs.gov/ltet

\section{Overview}

Land managers make decisions regarding restoration and rehabilitation actions that influence landscapes and ecosystems. Many of these decisions involve soil and vegetation manipulations, often known as land treatments. Historically, treatments were planned on a case by case basis with decisions derived from personal experience of past successes or failures. Current adaptive management strategies require a more structured and robust approach to the planning and implementation of land treatments.

The U.S. Geological Survey partnered with the Bureau of Land Management to create the Land Treatment Exploration Tool to facilitate adaptive management of land treatments. The Exploration Tool taps into a wealth of information about past treatments in the Land Treatment Digital Library (LTDL, https://ltdl.wr.usgs.gov/).

The Exploration Tool is designed for use by resource managers during the land treatment planning stage. This tool summarizes environmental characteristics of planned treatment areas and facilitates adaptive management practices by comparing those characteristics to similar legacy treatments.

\section{Here are the basics of how it works:}

1 Upload or draw a planned treatment area via an interactive - web map.

2 Explore land treatments, wildfires, and monitoring data that - overlap with the planned treatment area.

2. Calculate environmental characteristics, such as vegetation

5. composition, heat load, ruggedness, soils, average climate, and drought conditions of the planned treatment area.

1. Identify and explore details of past treatments that have - statistically similar climate, heat load, and landform characteristics relative to the planned treatment area.

5 Refine the results of the similarity analyses by filtering on a . variety of treatment characteristics.

6. Create custom reports for use in plans or other documents.

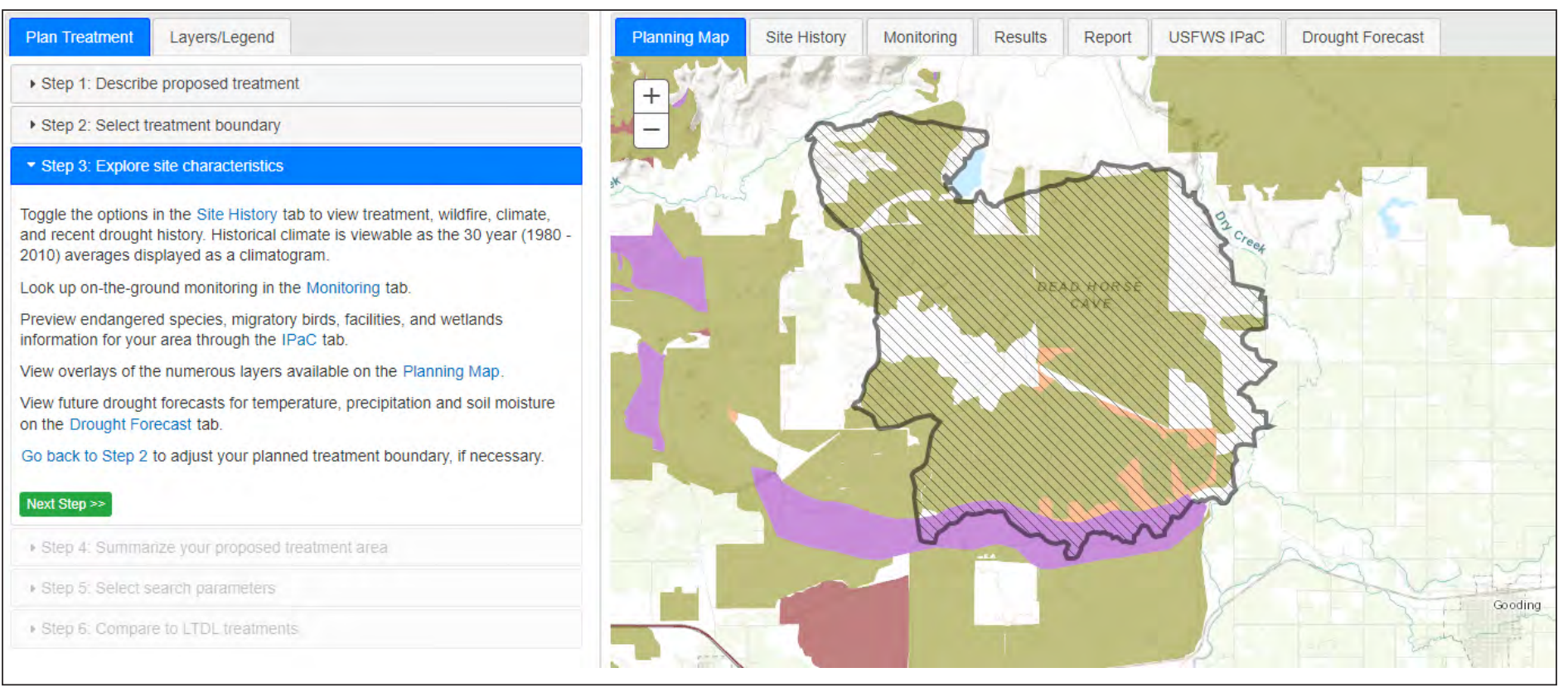

The Land Treatment Exploration Tool provides a practical resource for managers who are planning restoration and rehabilitation actions on public lands. The Exploration Tool is a user friendly, web-based interface to Geographic Information System (GIS) maps and tools, and requires little to no GIS experience to generate a variety of spatial products. Above is an example of the interactive map where the planning process begins. 


\section{Land Treatment Exploration Tool Features}

\section{Planned Treatment Area History and Summary Statistics}

The site history of the planned treatment area may inform treatment planning. Users can quickly identify the location and frequency of past disturbances, such as wildfires and land treatments, that have occurred within the planned treatment boundary, and export maps displaying these disturbances for use in plans and reports.

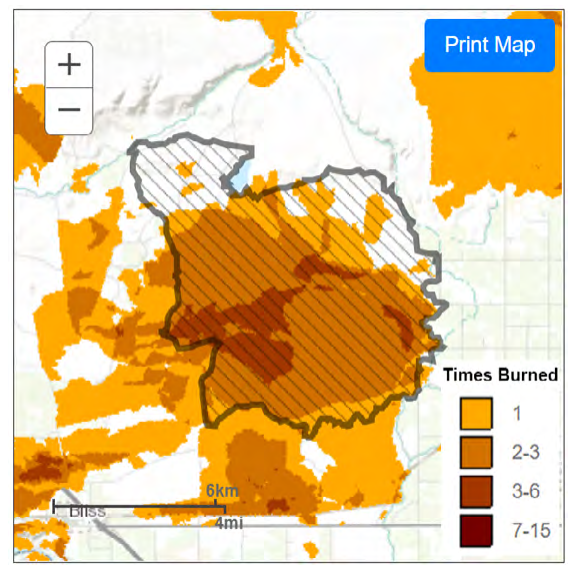

Users can summarize environmental data from multiple spatial layers that overlap their planned treatment area, such as prior monitoring, vegetation composition, elevation, climate, soil moisture and temperature regimes, and resistance and resilience classes.

\begin{tabular}{|c|c|c|c|}
\hline Category & Mean $\downarrow \uparrow$ & Range & St Dev $\downarrow \uparrow$ \\
\hline Elevation (ft) & 5711.29 & 1253.28 & 347.93 \\
\hline Max Temp ( $\left.{ }^{\circ} \mathrm{F}\right)$ & 55.78 & 5.11 & 1.46 \\
\hline Mean Temp ( $\left.{ }^{\circ} \mathrm{F}\right)$ & 44.56 & 2.84 & 0.58 \\
\hline Min Temp ( $\left.{ }^{\circ} \mathrm{F}\right)$ & 33.33 & 4.32 & 1.22 \\
\hline Precipitation (in) & 24.86 & 6.14 & 2.05 \\
\hline
\end{tabular}

\section{Explore Previous Land Treatment Information}

The Land Treatment Exploration Tool brings legacy land treatment information to your desktop by incorporating information from the Land Treatment Digital Library (https://ltdl.wr.usgs.gov/) directly into the tool.

Environmental similarities matter when comparing treatments. The Exploration Tool allows the user to run statistical similarity indices (climate, land form, and heat load) to help users identify past treatments that are the most similar to their planned treatment area.

The Exploration Tool provides an array of filters to allow users to narrow their search results to select and research only the most appropriate past treatments.

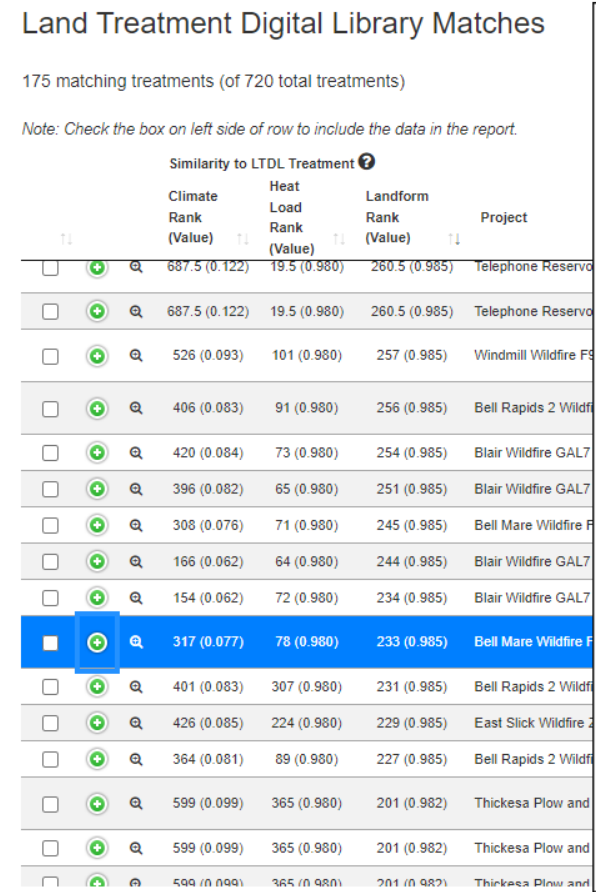

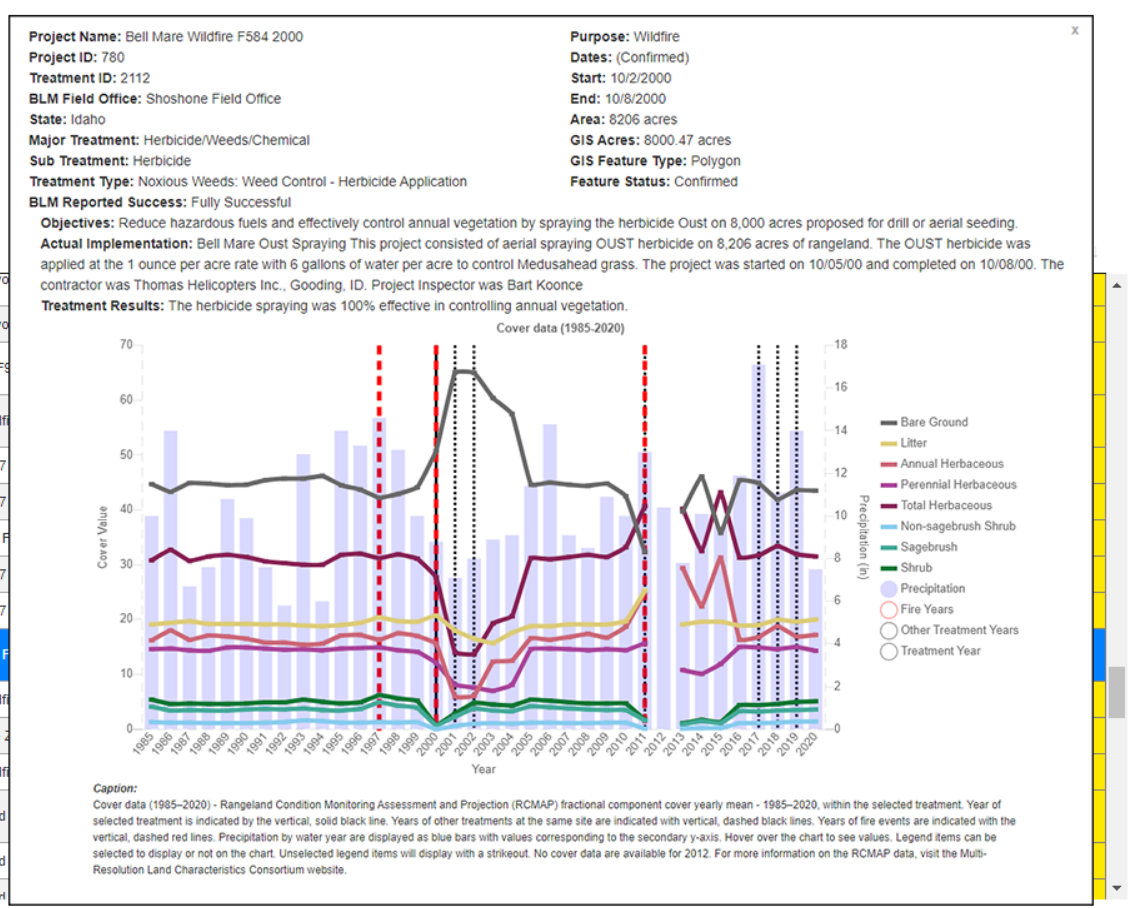

Banner photo credit: Justin Welty

ISSN 2327-6932 (online)

Authors: D.S. Pilliod, J.L. Welty, M.I. Jeffries, L.S. Schueck, and T.J. Zarriello 